\title{
Negative Pressure Pulmonary Edema Associated with Anterior Cervical Spine Surgery
}

\author{
Hideki Shigematsu ${ }^{1}$, Masana Yoneda ${ }^{1}$, Yasuhito Tanaka ${ }^{2}$ \\ ${ }^{1}$ Department of Orthopedic Surgery, Yamatotakada Municipal Hospital, Yamatotakada, Japan \\ ${ }^{2}$ Department of Orthopedic Surgery, Nara Medical University, Kashihara, Japan
}

We report a very rare case of negative pressure pulmonary edema (NPPE) that occurred immediately after anterior cervical discectomy and fusion (ACDF). The patient was a 25-year-old man who sustained a facet fracture-dislocation of C5 during a traffic accident. After ACDF, he developed NPPE and needed mechanical ventilation. Fortunately, he recovered fully within 24 hours. NPPE is a rare postoperative complication that may occur after cervical spine surgery. The aims of this report are to present information regarding the diagnosis and emergent treatment of NPPE, and to review the previous literature regarding this serious complication.

Keywords: Negative pressure pulmonary edema; Complication; Anterior cervical discectomy and fusion; cervical discectomy and fusion; Airway; Prevertebral soft tissue swelling; Cervical spine

\section{Introduction}

Anterior cervical discectomy and fusion (ACDF) is one of the most commonly performed spinal surgical procedures. The potential complications of this procedure include transient sore throat, dysphagia, hoarseness, dysphonia, laryngeal nerve paralysis, esophageal perforation and respiratory insufficiency due to upper airway obstruction. Airway compromise resulting from retropharyngeal hematoma or prevertebral soft tissue swelling may lead to respiratory distress and airway obstruction, requiring emergency re-intubation or tracheotomy.

Negative pressure pulmonary edema (NPPE) is a rare complication after ACDF. This complication occurs at a rate of almost 1 per 1000 patients (0.094\%) after all types of surgery [1]. Previous reports have attributed NPPE to upper airway obstruction. We report here a rare case of NPPE after ACDF.

\section{Case Report}

The patient gave informed consent for publication of this report. A 25-year-old man presented with neck pain after a traffic accident, but with no neurological symptoms. Plain radiography and computed tomography showed a left facet fracture of C5 (Figs. 1, 2); however, there were no signs of facet joint dislocation. He was treated with a hard cervical collar. Two weeks later, plain radiography showed a facet joint dislocation (Fig. 3). We performed open reduction from the posterior approach and ACDF at C4-C5 (Fig. 4). After confirming hemostasis, we placed a suction drain anterior to the cervical vertebrae.

The patient developed respiratory distress soon after the removal of the endotracheal tube. He had dyspnea with marked inspiratory effort and cyanosis due to upper airway obstruction. His saturation of peripheral oxygen decreased from $100 \%$ to $47 \%$. He was re-intubated and

Received May 16, 2013; Revised Jul 13, 2013; Accepted Sep 12, 2013

Corresponding author:Hideki Shigematsu

Department of Orthopedic Surgery, Yamatotakada City Hospital,

1-1 Isonokitamachi Yamatotakada, Nara 635-8501, Japan

Tel: +81-745-53-2901, Fax: +81-745-53-2908, E-mail: shideki@naramed-u.ac.jp 


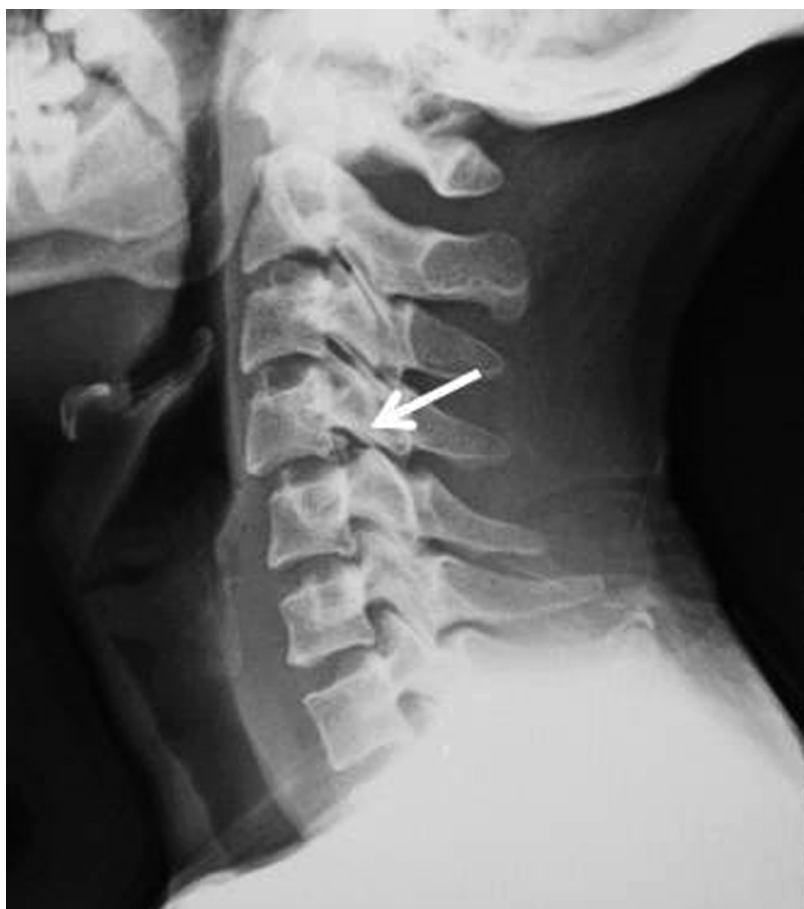

Fig. 1. Lateral radiograph on admission, showing a facet fracture of C5 (white arrow).

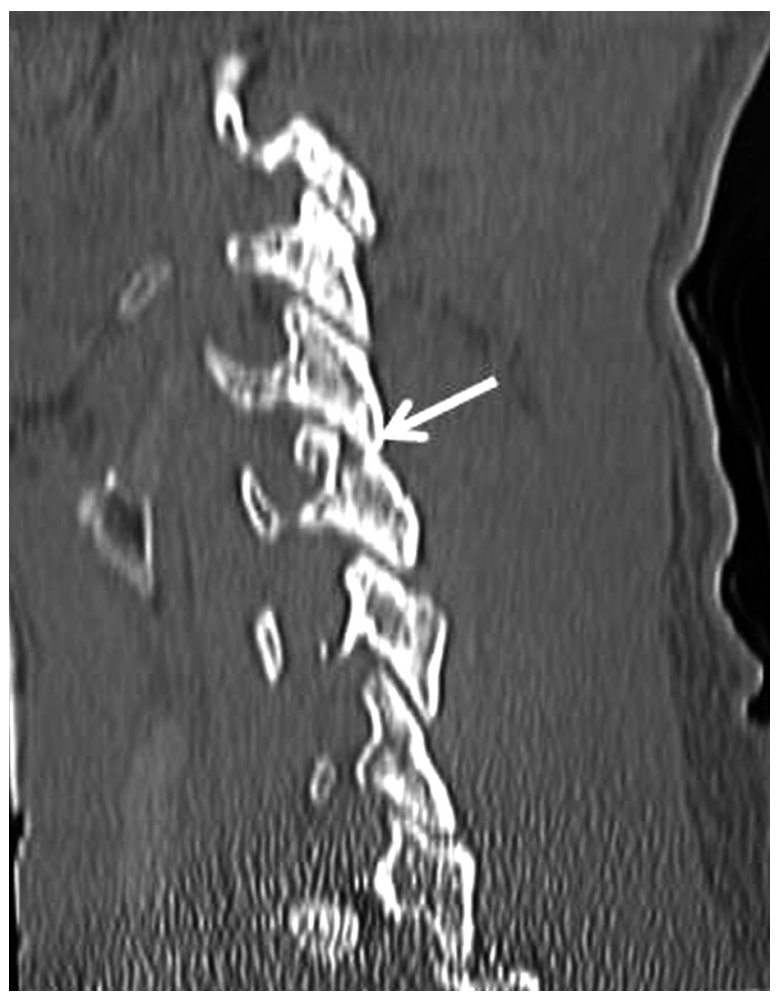

Fig. 2. Computed tomography (sagittal view) on admission, showing a facet fracture of C5 (white arrow).

ventilated with $100 \%$ oxygen by the anesthetist. Pink frothy sputum was observed in his airway. The cause of

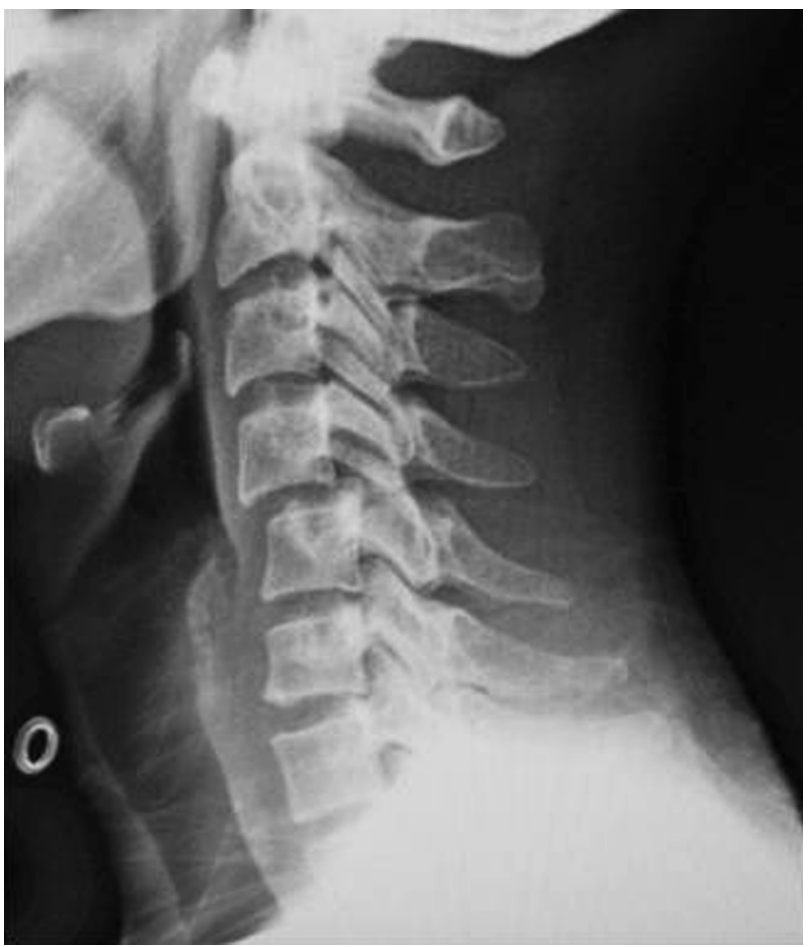

Fig. 3. Lateral radiograph after 2 weeks, showing dislocation of C4.

his respiratory symptoms was not immediately clear, and re-intubation or tracheotomy were the only treatment options. Chest X-ray showed pulmonary edema (Fig. 5). He was moved to the intensive care unit and received mechanical ventilation with positive end-expiratory pressure. After 18 hours, the pulmonary edema had improved and he was extubated uneventfully.

\section{Discussion}

NPPE presents with tachypnea and pulmonary crackles on auscultation, pink frothy sputum in the endotracheal tube, hypoxia on arterial blood gas analysis or pulse oximetry, and radiological changes. Although the cause of the respiratory symptoms in our patient was not immediately clear, we eventually diagnosed NPPE based on these findings.

Basically, NPPE is pulmonary edema associated with upper airway obstruction. ACDF may cause muscle and subperiosteal bleeding and soft tissue swelling, resulting in prevertebral soft tissue swelling. It is believed that the primary pathophysiologic events are related to the markedly negative intrapleural pressure associated with upper airway obstruction [2-5]. In acute airway obstruction, inspiration causes decreased intrathoracic pressure and 

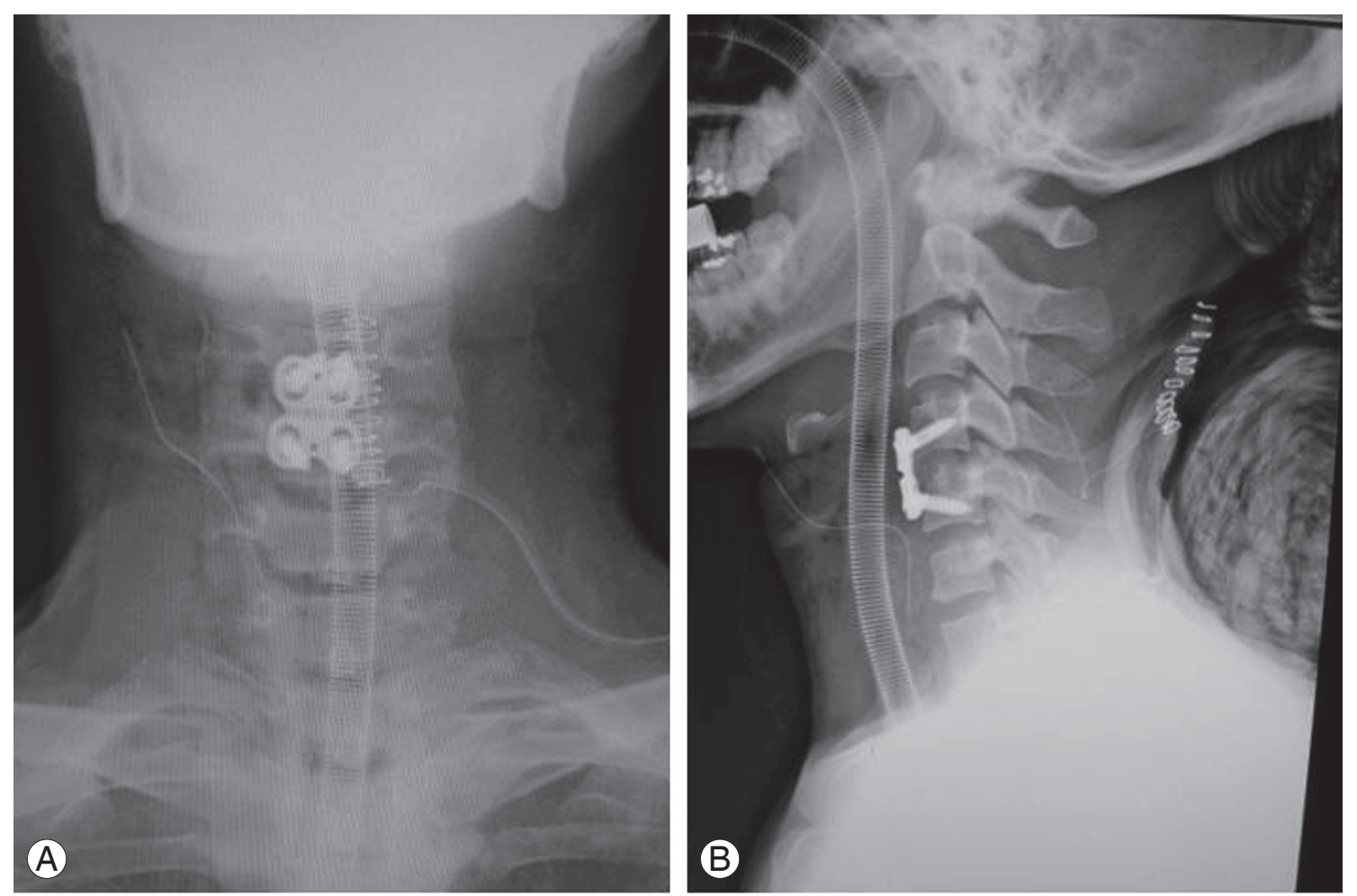

Fig. 4. Immediate postoperative radiographs. (A) Anteroposterior view. (B) Lateral view.

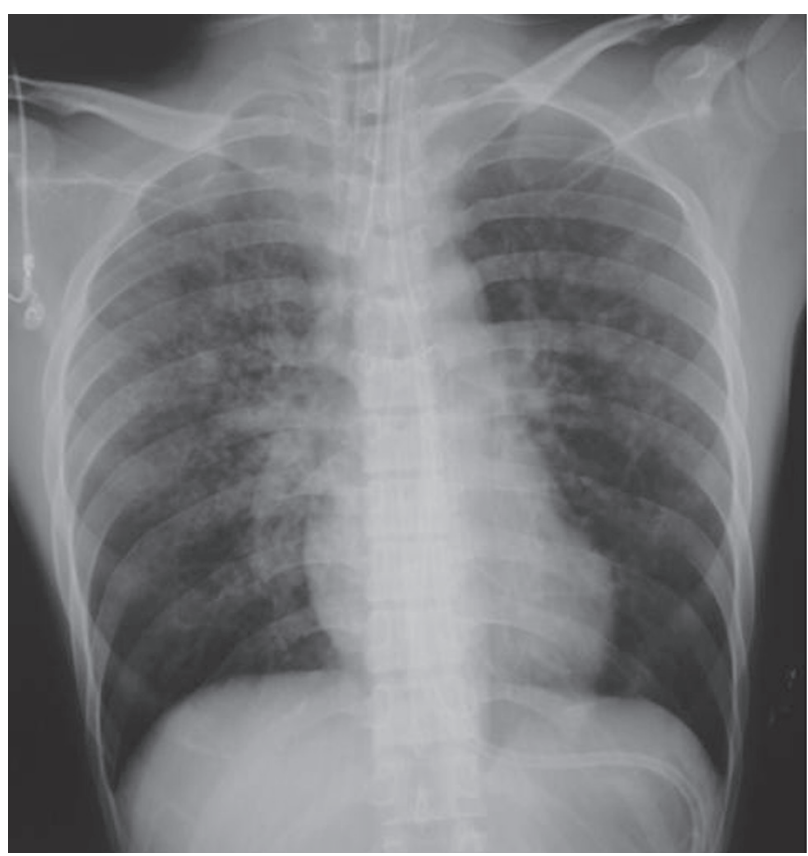

Fig. 5. Anteroposterior chest radiograph after acute airway obstruction, showing bilateral interstitial infiltrates consistent with pulmonary edema.

increased venous return. The increased pulmonary blood volume causes increased hydrostatic pressure and pulmo- nary vessel distension. Transudation from the capillary bed to the interstitium causes NPPE. Young and athletic patients can produce strong inspiratory effort, and NPPE commonly develops in these patients.

In our patient, we think that the upper airway obstruction was caused by prevertebral soft tissue swelling related to ACDF, or to laryngospasm. However, it is difficult to determine the exact cause. The reported incidence of laryngospasm after general anesthesia ranges from $0.05 \%$ to $1 \%$ [6], whereas the reported incidence of airway complications after anterior cervical surgery is $5 \%$ to $6 \%$ [7].

The treatment for NPPE is well established $[8,9]$. Halow and Ford [10] reviewed nineteen previous reports and summarized this treatment in their report. Half of the patients may be successfully ventilated with a bag/mask, and $70 \%$ require re-intubation. Re-intubation is notably difficult, and the use of muscle relaxant or sedation is required in $60 \%$ of patients. Pulmonary edema develops within 10 to 90 minutes after upper airway obstruction, and usually resolves rapidly ( $70 \%$ of cases resolve within 24 hours). There are no long-term sequelae after recovery. Mechanical ventilation may be required, but can be withdrawn within 24 hours in all patients. Our patient was also weaned from mechanical ventilation within 
24 hours. Positive end-expiratory pressure $(5-10 \mathrm{~cm}$ $\mathrm{H}_{2} \mathrm{O}$ ) is used in nearly all patients treated with mechanical ventilation. Furosemide is the most frequently used medication (50\% of patients). Other medications, such as digoxin, theophylline and steroids, have also been used; however, the efficacy of these treatments has not been proven.

Doctors should be aware of the requirements for diagnosis, early detection and treatment of NPPE after cervical spine surgery. Patients with an increased risk of NPPE should be informed of this risk preoperatively by the surgeon and the anesthetist.

This is the first report of obstruction of the upper airway after ACDF leading to NPPE. This very rare, but potentially lethal, complication occurs in the early postoperative period. We recommend that spine surgeons should inform patients undergoing ACDF of this potential complication, particularly to young and athletic patients.

\section{Conflict of Interest}

No potential conflict of interest relevant to this article was reported.

\section{References}

1. Deepika K, Kenaan CA, Barrocas AM, Fonseca JJ, Bikazi GB. Negative pressure pulmonary edema after acute upper airway obstruction. J Clin Anesth 1997; 9:403-8.

2. Robotham JL, Stuart RS, Doherty K, Borkon AM,
Baumgartner W. Mitral and aortic blood flows during spontaneous respiration in dogs. Anesthesiology 1988;69:516-26.

3. Smith-Erichsen N, Bo G. Airway closure and fluid filtration in the lung. Br J Anaesth 1979;51:475-9.

4. Loyd JE, Nolop KB, Parker RE, Roselli RJ, Brigham KL. Effects of inspiratory resistance loading on lung fluid balance in awake sheep. J Appl Physiol 1986;60: 198-203.

5. Leatherman JW, Schwartz S. Pulmonary edema due to upper airway obstruction. South Med J 1983;76: 1058-60.

6. Westreich R, Sampson I, Shaari CM, Lawson W. Negative-pressure pulmonary edema after routine septorhinoplasty: discussion of pathophysiology, treatment, and prevention. Arch Facial Plast Surg 2006;8:8-15.

7. Lee SH, Kim KT, Suk KS, Park KJ, Oh KI. Effect of retropharyngeal steroid on prevertebral soft tissue swelling following anterior cervical discectomy and fusion: a prospective, randomized study. Spine (Phila Pa 1976) 2011;36:2286-92.

8. Willms D, Shure D. Pulmonary edema due to upper airway obstruction in adults. Chest 1988;94:1090-2.

9. Herrick IA, Mahendran B, Penny FJ. Postobstructive pulmonary edema following anesthesia. J Clin Anesth 1990;2:116-20.

10. Halow KD, Ford EG. Pulmonary edema following post-operative laryngospasm: a case report and review of the literature. Am Surg 1993;59:443-7. 